ISSN: 2576-8875

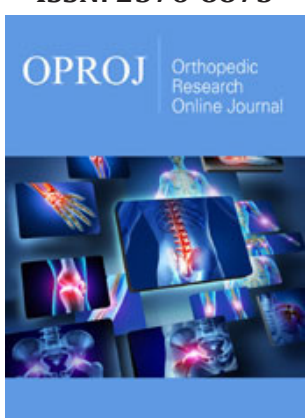

*Corresponding author: Sana ullah, FCPS Ortho, consultant orthopedic and sports surgeon, Pakistan

Submission: 海 August 11, 2021

Published: 此 September 01, 2021

Volume 8 - Issue 4

How to cite this article: Muhammad Waqar, Sana Ullah, Muhammad Saeed, Israr Ahmad, Zeeshan Khan, Muhammad Arif Khan. Outcomes of Arthroscopic ACL Reconstruction Using Adjustable Loop Endobutton and Bioabsorbable Screw for Hamstring Autograft. Ortho Res Online J. 8(4). OPROJ. 000695. 2021.

DOI: 10.31031/OPROJ.2021.08.000695

Copyright@: Sana Ullah, This article is distributed under the terms of the Creative Commons Attribution 4.0 International License, which permits unrestricted use and redistribution provided that the original author and source are credited.

\section{Outcomes of Arthroscopic ACL Reconstruction Using Adjustable Loop Endobutton and Bioabsorbable Screw for Hamstring Autograft}

\author{
Muhammad Waqar', Sana Ullah ${ }^{2 *}$, Muhammad Saeed ${ }^{1}$, Israr Ahmad ${ }^{1}$, Zeeshan \\ Khan $^{1}$ and Muhammad Arif Khan ${ }^{1}$ \\ ${ }^{1}$ Department of Orthopedic and Spine Surgery Hayatabad Medical Complex Peshawar, \\ Pakistan \\ ${ }^{2}$ FCPS Ortho, Consultant Orthopedic and Sports Surgeon, Pakistan
}

\begin{abstract}
Background: Anterior Cruciate Ligament injury is the most common knee ligament injury. ACL tear can be reconstructed openly but endoscopic reconstruction is the gold standard. It is usually repaired using BPTB or Hamstring autograft. The graft is supported using adjustable loop endobutton at the femoral end while bioabsoarbable interference screw at the tibial end. Our aim was to study the outcomes of particular method of fixation for fixing the quadrupled hamstring autograft.
\end{abstract}

Methods: In this study 160 patients with ACL injury were treated with arthroscopic reconstructed using hamstring autograft. The graft was fixed with endobutton on the femoral side while bioabsorbable screw was used at the tibial end. The prospective assessment was done using IKDC scoring system.

Results: According to subjective IKDC scoring, 120 (75\%) results were excellent, 24(15\%) were good, $12(7.5 \%)$ were satisfactory and $4(2.5 \%)$ were bad. Now in $97.5 \%$ patients the state of knee joint is very good compared to preoperative state.

Conclusion: Of all the 160 patients underwent ACL reconstruction, 156(97.5\%) patients are satisfied with the results of the operation.

\section{Introduction}

Anterior cruciate ligament tears are the most common knee injuries in adult population with the rise in participation in sports as well as road traffic accidents. Anterior Cruciate Ligament (ACL) rupture is a disastrous condition that can cause instability, chronic pain and early degenerative changes [1,2]. In Pakistan, most of the patients are unaware of the nature of injury and available surgical treatment options. They rely mostly on conservative treatment without consulting an orthopedic sports surgeon. As the time passes, the degenerative changes start appearing with pain and instability during walking. They usually present after significant time had passed.

Anterior cruciate ligament can be reconstructed through open and arthroscopic techniques. Arthroscopic ACL reconstruction is the standard technique to treat ACL tear $[3,4]$. This procedure has reduced postoperative morbidity and enables early active physiotherapy [5]. 
The most commonly used grafts are Bone-Patellar TendonBone (BPTB) or hamstring auto grafts [6]. Although both the techniques have advantages and disadvantages, hamstring auto graft technique is preferred, due to low morbidity of donor site and excellent biomechanical graft properties [7]. The most devastating complication is the graft rupture after ACL reconstruction which requires a revision surgery.

The graft fixation methods include interference screw (aperture fixation), end button (suspensory fixation method) and trans-condylar rigid fixation [8]. To withstand the huge number of forces on the graft due to early rehabilitation exercises, weight bearing and return to sports activities, a secure fixation technique is required [9].

The aim of this study is to analyze the outcomes of arthroscopic ACL reconstruction with quadrupled hamstring auto graft in the femoral tunnel using adjustable loop endobutton at the femoral end and bio absorbable interference screw at the tibial end.

\section{Materials and Methods}

This prospective observational study was approved by ethics committee of Hayatabad Medical Complex Peshawar. Informed consent was obtained from each patient. All the patients presented with anterior cruciate ligament injury in the out patient department were treated with arthroscopic reconstruction using hamstring quadrupled graft. They were evaluated and followed up regularly. 160 patients underwent arthroscopic ACL reconstruction from January 2017 to November 2020. Both male and female patients, operated for ACL reconstruction were included in the study. They were all above 18 years of age and willing to participate in the study. Informed consent was taken. Recurrent ACL tear, concurrent fracture, associated posterior cruciate ligament injury, medial or lateral collateral ligament injury and patients who are not willing to provide voluntary informed consent were excluded from the study. Complete clinical history and physical examination was performed in all cases. The specific tests used to test ACL tear included Lachmann test, anterior drawer test and pivot shift test. Results were graded as 0 (negative) $,+1,+2$ and +3 positive. Other routinely performed tests included varus and valgus stress test, mc Murrays test, posterior drawer test and reverse pivot shift test were also performed. Radiographs included standard AP and lateral views of the affected knee. MRI of affected knee was done in all cases. Pre-operative dose of antibiotics was given half an hour before incision. After induction of anesthesia, tourniquet applied to upper thigh and patient placed in supine position. Specific clinical tests performed under anesthesia. Incisions made for anteriomedial and anteriolateral portals. Diagnostic arthroscopy performed to confirm ACL tear. We started with harvesting hamstring graft. Oblique incision made about $3 \mathrm{~cm}$ antero-medially on proximal tibia starting $3-4 \mathrm{~cm}$ distal to joint line and $3-4 \mathrm{~cm}$ medially to tibial tuberosity. It is pulled with curved clamp and freed end of graft whip stitched with size 2 vicryl suture, using closed tendon stripper the graft is harvested. The tendon was prepared in quadrupled graft. The size depending on the length of the tendon, $7 \mathrm{~cm}$ being the minimum accepted length for final graft. Vicryl sutures were used for preparation of proximal and distal ends of the graft. Femoral tunnel was prepared using anteromedial port with knee in maximum flexion ( $>120$ degree). Tibial tunnel was prepared using tibial guide. Passing suture was used to pull the loop of adjustable endobutton from tibial tunnel into femoral tunnel. The endobutton was flipped against the lateral cortex by gently pulling the string and then loop of endobutton tightened to fill femoral tunnel completely with graft. Appropriate size (one size bigger) bio absorbable interference screw used to fix the graft at the tibial end in extension of the knee. The skin is closed using prolene 2/0 suture. Iv antibiotics were given for a period of 3 days postoperatively. Knee immobilizer was applied for a period of four weeks to protect the ligament. Range of motion of the knee and physiotherapy was started the day after the surgery and gradually progressed. Knee flexion of more than 90 degrees and full weight bearing allowed 1 month postoperatively. Patients were advised regular follow-up for the next 6 months.

\section{Results}

This prospective study of ACL reconstruction using hamstring quadrupled auto graft was conducted in the department of Orthopedics and Spine in Hayatabad medical complex Peshawar and a private clinic. 160 patients underwent ACL reconstruction surgery from January 2017 to November 2020. All patients were followed up for 6 months and evaluated. Out of 160 patients 156(97.5\%) were male and $4(2.5 \%)$ were female. $120(75 \%)$ patients had right sided ACL injury while $40(25 \%)$ patients had left sided ACL injury. There were no bilateral cases in this study. If we compare the patients on the basis of mode of injury, 114(71\%) patients had sports injury, 40(25\%) patients had Road Traffic Accident and 6(4\%) patients had other modes of injury like fall or slip etc. The age of patient ranged from 18 to 56 years with mean age of 25 years as shown in the Table 1 . The ratio of right knee to left knee involved in ACL injury was 3:1. Majority of the patients $108(67.5 \%)$ were operated after 6 months of injury while $52(32.5 \%)$ patients were operated before 6 months of injury. Most of the cases 120(75\%) presented with a feeling of giving way of knee during routine work or walking with pain with or without locking while $40(25 \%)$ cases had the feeling of giving way only during sports or heavy labor usually with pain with or without locking (Figure 1\&2).

Table 1: Basic data.

\begin{tabular}{|c|c|c|}
\hline \multirow{2}{*}{ Gender } & Male & 156 \\
\cline { 2 - 3 } & Female & 4 \\
\hline \multirow{2}{*}{ Knee Side } & Right Knee & 120 \\
\cline { 2 - 3 } & Left Knee & 40 \\
\hline \multirow{3}{*}{ Mode of Injury } & RTA & 114 \\
\cline { 2 - 3 } & Sports & 40 \\
\cline { 2 - 3 } & Miscellineous & 6 \\
\hline
\end{tabular}




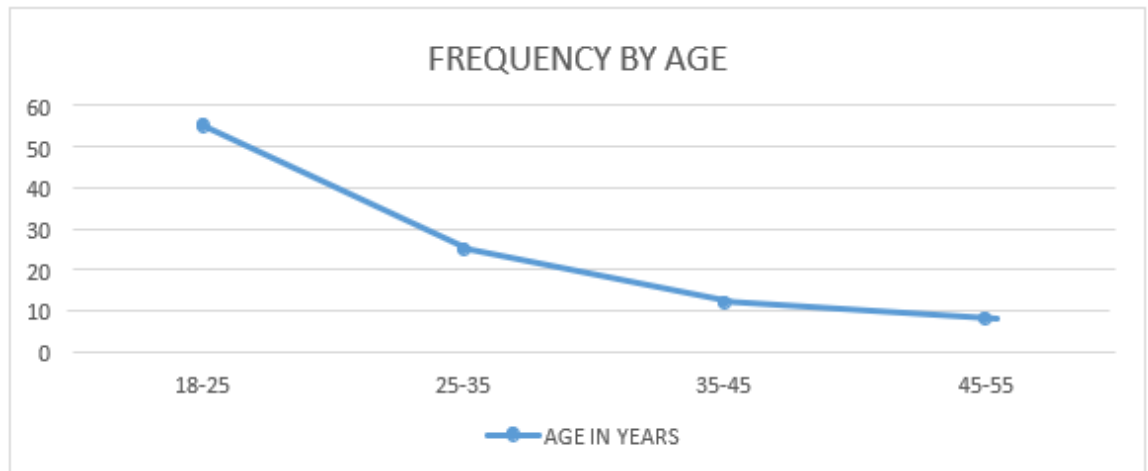

Figure 1: Frequency of patients by age.

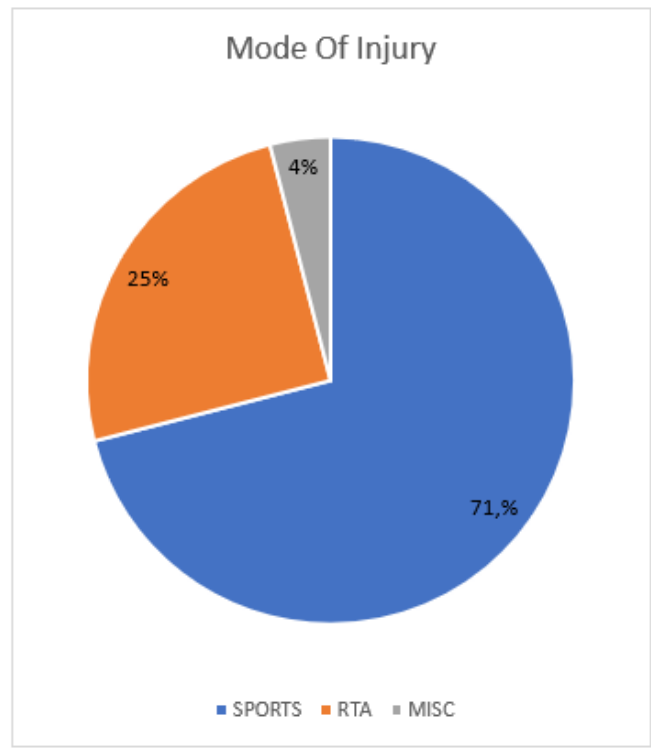

Figure 2: Mode of injury.

We assessed the functional outcome of patients through preoperative and post-operative IKDC scoring. The mean of the preoperative IKDC scoring was 41 with SD of 9 and the mean of the pos-toperative IKDC scoring was 81 with SD of 12 . We analyzed the data through SPSS 20 software and applied paired t test. The $p$ value came out to be 0.0001 which is highly statistically significant.

After preoperative evaluation of patients with ACL injury, majority $100(62.5 \%)$ of cases were in group C (abnormal), followed by $48(30 \%$ ) in group B (severe abnormal) and $12(7.5 \%)$ cases were in group D (near abnormal) as shown in Figure 3 (Table2).

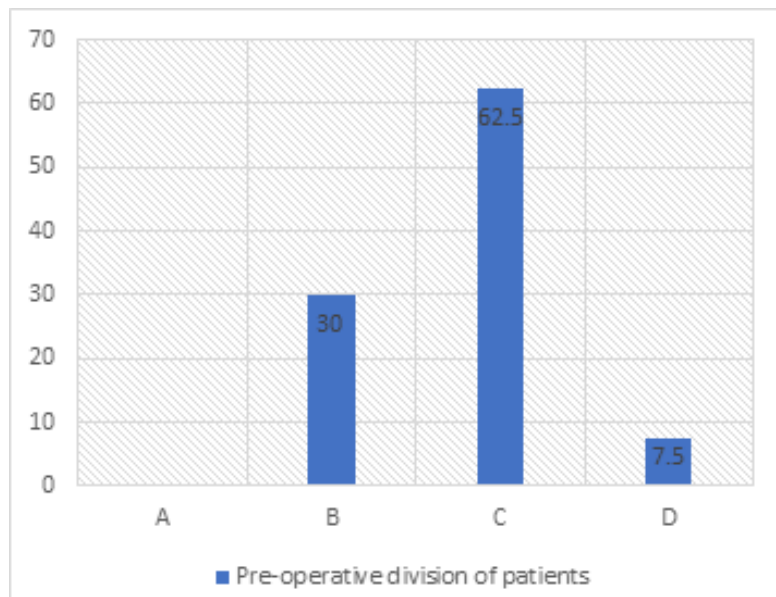

Figure 3: Preoperative division of patients. 
Table 2: IKDC objective knee joint examination form.

\begin{tabular}{|c|c|c|c|c|}
\hline & A (normal) & B (nearly normal) & C (abnormal) & D (severely abnormal) \\
\hline Effusion & none & mild & moderate & severe \\
\hline $\begin{array}{l}\text { Passive motion deficit: } \\
\text { lack of extension }\end{array}$ & $<3^{\circ}$ & $3-5^{\circ}$ & $6-10^{\circ}$ & $>10^{\circ}$ \\
\hline lack of flexion & $0-5^{\circ}$ & $6-15^{\circ}$ & $16-25^{\circ}$ & $>25^{\circ}$ \\
\hline $\begin{array}{l}\text { Ligament examination: } \\
\text { Lachman }\left(25^{\circ} \text { flex }\right) \text { manual max }\end{array}$ & $1-2 \mathrm{~mm}$ & $3-5 \mathrm{~mm}$ & $6-10 \mathrm{~mm}$ & $>10 \mathrm{~mm}$ \\
\hline Anterior endpoint & firm & & soft & \\
\hline Total AP translation $\left(70^{\circ}\right.$ flex $)$ & $0-2 \mathrm{~mm}$ & $3-5 \mathrm{~mm}$ & $6-10 \mathrm{~mm}$ & $>10 \mathrm{~mm}$ \\
\hline Pivot Shift & equal & glide & clunk & gross \\
\hline \multicolumn{5}{|l|}{ Compartment findings: } \\
\hline Crepitus anterior compartment & none & moderate & crepitation & crepitation \\
\hline Crepitus medial compartment & & & with & with \\
\hline Crepitus lateral compartment & & & mild pain & acute pain \\
\hline Harvest site pathology & none & mild & moderate & severe \\
\hline $\begin{array}{c}\text { X-ray findings: } \\
\text { Medial joint space } \\
\text { Lateral joint space } \\
\text { Patellofemoral }\end{array}$ & none & mild & moderate & severe \\
\hline
\end{tabular}

In $120(75 \%)$ cases the results were very good after ACL reconstruction as shown in Figure 4. About 24(15\%) cases reported good and in $12(7.5 \%)$ cases the results were satisfactory. The remaining $4(2.5 \%)$ cases were having bad results. At present
$48(30 \%)$ patients have returned to intensive sport activities; $88(55 \%)$ patients have medium sport activity while $24(15 \%)$ patients have small sport activities.

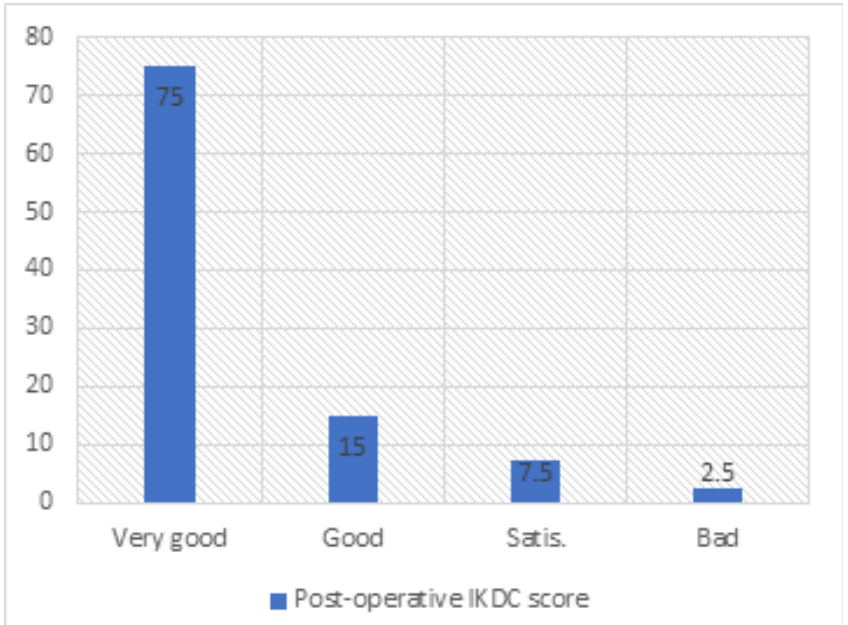

Figure 4: Postoperative IKDC scoring.

\section{Discussion}

Anterior cruciate ligament reconstruction using arthroscopic technique has become the most successful and standard surgical technique [10]. The goal of this technique is to regain the stability on the knee. The optimal timing of surgery is still a debate in the literature. Smith et al proposed from their systemic reviews that the clinical outcomes were almost same in comparing early (less than 3 weeks ) and delayed (greater than 6 weeks) ACL reconstruction; however this conclusion has limitations, such as non-randomization and lack of appropriate blinding [11]. All the patients in our study underwent ACL reconstruction with hamstring quadrupled fold auto graft fixed with endobutton at the femoral end and a bioabsorbable interference screw at the other tibial tunnel. In a study conducted by Cooley et al on ACL reconstruction using quadrupled folded semi-tendinosus graft, they concluded that this method provides excellent clinical outcomes and patients regains almost 
pre-injury activities [12]. Rarely the degeneration of the articular surfaces occurs and the re-operation rates are minimal. The endobutton used is not directly fixed into the graft; there is a fiber wire thread present between the endobutton and the graft. This suspensory fixation is associated with increased anterior knee joint laxity [13]. In this study we found 10 patients had grade 1 laxity after 6 months and grade 2 laxities in 4 patients after at the end of final follow-up. This study clearly demonstrates the majority of ACL tear occur during sports activities and road accidents. In this study the subjective IKDC score is 90 points which is in accordance with the 90 points of Siebold et al using hamstring auto graft and endobutton and 85 and 82 points of Aglietti et al. [13] using double strand hamstring autograft $[14,15]$. $90 \%$ cases of ACL tear reported their knees as normal or near normal (group a \& b) after reconstruction which is in accordance with the $94 \%$ reported by Johma et al. [16] at 5 years follow-up using either BPTB graft or hamstring, and $92 \%$ of Siebold et al using endobutton $[14,16]$.

\section{Conclusion}

It is purposeful to perform Arthroscopic ACL reconstruction using hamstring auto graft with endobutton on the femoral end and bioabsorbable screw at the tibial end as $95 \%$ of the patients are satisfied with the results.

\section{References}

1. Thompson SM, Salmon LJ, Waller A, Linklater J, Roe JP, et al. (2016) Twenty-year outcome of a longitudinal prospective evaluation of isolated endoscopic anterior cruciate ligament reconstruction with patellar tendon or hamstring autograft. Am J Sports Med 44: 2579-2588.

2. Cohen M, Amaro JT, Ejnisman B, Carvalho RT, Nakano KK, et al. (2007) Anterior cruciate ligament reconstruction after 10 to 15 years: association between meniscectomy and osteoarthrosis. Arthroscopy 23: 629-634.

3. Jagtap V, Gorgile N, Shah Y, Rokade V, Bartakke G (2017) Functional outcome of an arthroscopic anatomical single bundle anterior cruciate ligament reconstruction using semi-tendinosus graft with fixation using endobutton on femoral side and suture disc on tibial side: a prospective clinical study. Int J Res Orthop 3: 1175-1179.

4. Apostolopoulos A, Nakos A, Nikolopaulos D, Theophanopaulos F, Liarokapis S, et al. (2009) ACL reconstruction with hamstring tendon autografts. EEXOT 60(1): 48-52.
5. Delay BS, Smolinski RJ, Wind WM (2001) Current practices and opinions in ACL reconstruction and rehabilitation: results of a survey of the American Orthopedic Society for Sports Medicine. Am J Knee Surg 14: 85-89.

6. Tibor L, Chan PH, Funahashi TT, Wyatt R, Maletis GB, et al. (2016) Surgical technique trends in primary ACL reconstruction from 2007 to 2014. J Bone Joint Surg Am 98: 1079-1089.

7. Lawhorn KW, Howel SM (2007) Principles for using hamstring tendons for anterior cruciate ligament reconstruction. Clin in Sports Med 26(4): 567-585.

8. Frank C, Jackson D (1997) The science of reconstruction of the anterior cruciate ligament. J Bone Joint Surg Am 79(10): 1556-1576.

9. Brand J, Weiler A, Caborn DN, Brown CH Jr, Johnson DL (2000) Graft fixation in cruciate ligament reconstruction. Am J Sports Med 28: 761774 .

10. Robindro P, Latchumi NVK, Kanthimathi BD (2016) To study the functional outcome of arthroscopic ACL reconstruction using hamstring graft fixed with endobutton for femur and interference screw and suture post for tibial fixation. Int J Med Dent Sci 5(1): 978-983.

11. Smith TO, Davies L, Hing CB (2010) Early versus delayed surgery for anterior cruciate ligament reconstruction: a systematic review and metaanalysis. Knee Surg Sports Traumatol Arthrosc 18(3): 304-311.

12. Cooley V, Deffner K, Rosenberg T (2001) Quadrupled semitendinosus anterior cruciate ligament reconstruction: 5-year results in patients without meniscus loss. Arthroscopy 17(8): 795-800.

13. Aglietti P, Buzzi R, Menchetti PM, Giron F (1996) Arthroscopically assisted semitendinosus and gracilis tendon graft in reconstruction for acute anterior cruciate ligament injuries in athletes. Am J Sports Med 24(6): 726-731.

14. Siebold R, Dehler C, Ellert T (2008) Prospective randomized comparison of double bundle versus single bundle anterior cruciate ligament reconstruction. J Arth Related Surg 24(2): 137-145.

15. Aglietti P, Giron F, Buzzi R, Biddau F, Sasso F (2004) Anterior cruciate ligament reconstruction: bone-patellar tendon-bone compared with double semitendinosus and gracilis tendon grafts. J Bone Joint Surg Am 86(10): 2143-2155.

16. Jomha NM, Pinczewski LA, Clingelffer AJ, Otto DD (1999) Arthroscopic reconstruction of the anterior cruciate ligament with pateller-tendon autograft and interference screw fixation. J Bone Joint Surg Br 81(5): 775-779. 